\title{
Computerized Tomography Technique for the Investigation of the Maxillary First Molar Mesiobuccal Root
}

\author{
Stefano Corbella, ${ }^{1}$ Massimo Del Fabbro, ${ }^{2}$ Igor Tsesis, ${ }^{3}$ and Silvio Taschieri ${ }^{2}$ \\ ${ }^{1}$ Centre for Research in Oral Implantology, Department of Biomedical, Surgical and Dental Sciences, Università degli Studi di Milano, \\ IRCCS Istituto Ortopedico Galeazzi, Milan, Italy \\ ${ }^{2}$ Centre for Research in Oral Health, Department of Biomedical, Surgical and Dental Sciences, Università degli Studi di Milano, \\ IRCCS Istituto Ortopedico Galeazzi, Milan, Italy \\ ${ }^{3}$ Section of Endodontology, The Maurice and Gabriela Goldschleger School of Dental Medicine, Tel Aviv University, Israel
}

Correspondence should be addressed to Massimo Del Fabbro; massimo.delfabbro@unimi.it

Received 25 April 2013; Accepted 6 August 2013

Academic Editor: Eyal Rosen

Copyright (C) 2013 Stefano Corbella et al. This is an open access article distributed under the Creative Commons Attribution License, which permits unrestricted use, distribution, and reproduction in any medium, provided the original work is properly cited.

\begin{abstract}
The aim of this paper was to review the literature about the use of computerized tomography to evaluate the presence and characteristics of the second mesiobuccal canal in the maxillary first molar. An electronic search was performed. Frequencies of the presence of second mesiobuccal canal and root anatomy characteristics were extracted from the selected studies. Pooled frequencies were calculated as weighted means. Seven articles were included. A second mesiobuccal canal was present in $59.32 \%$ of the teeth, and it was noncommunicating in $58.45 \%$ of teeth presenting the canal itself. The most common root canal morphology was single canal or two separated canals. The present paper showed that cone beam CT is a viable radiologic device for the evaluation of the mesiobuccal root of maxillary first molars. In fact, it was observed that the frequency of second mesiobuccal canal detection is similar to those presented by clinical studies or micro-CT evaluations.
\end{abstract}

\section{Introduction}

A sound knowledge of root canal anatomy is mandatory in order to perform an adequate root canal treatment. Studies reported that failure to detect all the canals present in a root canal system was one of the causes of failure of endodontic therapy [1-6].

A number of studies that evaluated the anatomy of mesiobuccal roots of maxillary permanent first molars reported a wide range of anatomical variations [7-10].

It was hypothesized that failure to detect, debride, and fill a second mesiobuccal canal (MB2) of first permanent maxillary molars was one of the main causes of poor long-term prognosis after root canal treatment in these teeth [11, 12].

While many ex vivo studies investigated the presence of a mesiobuccal canal using canal staining, cross-sectioning, and dentine examination through magnification devices [13-15], the most used technique to investigate the anatomy of these teeth prior to an endodontic treatment is periapical radiography, which does not allow a complete detailed evaluation of the root canal anatomy [16].

Cone-beam computed tomography (CBCT) was developed in the 1990s with the aim of producing maxillofacial three-dimensional images using a lower radiation dose than conventional computed tomography (CT) $[17,18]$. The characteristics of the CBCT scanning were described as well suited to the endodontic field because of the higher accuracy of the device in comparison to that of the standard CT $[17,19]$.

Despite the known limitations of the CBCT (scattering [20], lower resolution than conventional radiography [17, 21]), it proved to be valuable in endodontic therapy for the diagnosis and evaluation of root canal anatomy [17].

The aim of the present paper was to systematically review the current scientific literature about the use of CT for the investigation of the mesiobuccal roots and canals of first permanent maxillary molars. 


\section{Materials and Methods}

2.1. Search Strategy. The following electronic databases were searched: MEDLINE (through PubMed interface http:// www.ncbi.nlm.nih.gov/sites/pubmed), Scopus (http://www .scopus.com/), EMBASE (http://www.embase.com/), and the Cochrane Library (http://www.cochrane.org/). A search string was prepared ad hoc combining keywords with the use of Boolean operators "AND" and "OR". The search string was ("Cone Beam Computed Tomography" OR "Cone Beam CT" OR "CBCT" OR “Computed Tomography" OR "CT") AND ("endodontics" OR "endodontic diagnosis" OR "maxillary first molar" OR "fourth canal" OR "dental anatomy" OR "root canal" OR "mesiobuccal canal"). Results were limited by year of publication (from 1970 on), and the last search was performed in September 2012. In addition, a manual forward and backward search was performed in the reference lists of selected articles from the search results and of articles from the search results that were published in Journal of Endodontics, International Endodontic Journal, Oral Surgery Oral Medicine Oral Pathology Oral Radiology and Endodontology, Journal of Dentistry, Journal of Dental Research, Clinical Oral Investigations, European Journal of Oral Sciences, Odontology, Dentomaxillofacial Radiology, Oral Radiology, Australian Dental Journal, and Australian Endodontic Journal. No language restriction was posed.

2.2. Study Selection Criteria. The following inclusion criteria had to be met in order to be included in the review:

(1) any study design (prospective or retrospective);

(2) ex vivo or in vivo studies;

(3) root canal anatomy evaluated using CT;

(4) at least 10 teeth analyzed;

(5) description of presence/absence of MB2 in maxillary first molars;

(6) clear description of tooth type and location.

Studies not meeting the above criteria were excluded from the review.

2.3. Data Extraction and Analysis. The following parameters were recorded in an electronic form:

(i) presence/absence of the MB2 in maxillary first molars;

(ii) any anatomical characteristics of the MB2, as described by Vertucci [29];

(iii) methods for detection and CBCT machine characteristics.

Risk of bias was assessed for each of the included studies, considering the following parameters:

(i) number of examined teeth, posing that when less than 50 teeth were evaluated, the study had a moderate risk of bias; otherwise, the risk of bias for this parameter was judged as low;

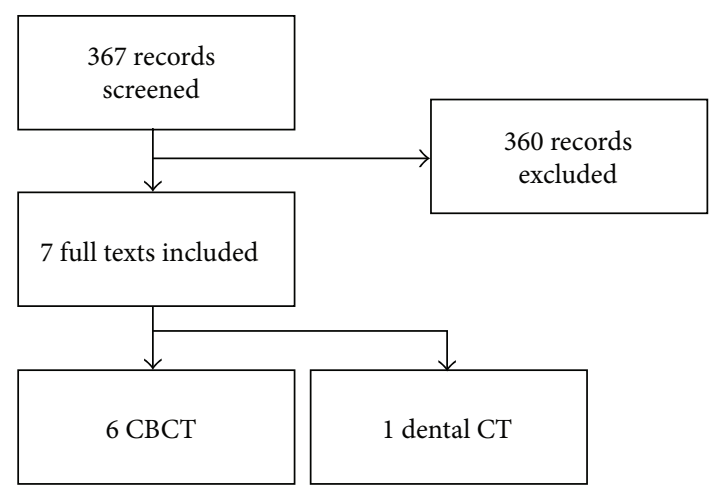

FIgURE 1: Article selection process.

(ii) quality of data reporting, considering that if the authors did not report the characteristics of the root canal anatomy of MB2, but only the presence/absence of the canal, the study was judged at moderate risk of bias;

(iii) fulfilment of the aims of the study, reporting of individual data instead of frequency percentages, and clear description of population characteristics were evaluated, and when missing, a moderate risk of bias was assigned.

Pooled data were analyzed through an evaluation of the weighted mean prevalence of MB2. Weighted means were calculated for the frequencies of different mesiobuccal canals morphologies following the Vertucci classification [29]. Moreover, a critical evaluation of differences among the various detection methods in terms of presence/absence of MB2 was performed.

\section{Results}

Article selection process is summarized in the flowchart shown in Figure 1. The electronic search yielded 367 articles. After title and abstract screening, 20 articles were selected for full-text evaluation. The article selection was performed independently by two authors (SC and MDF). In case of disagreement, a joint decision was taken by discussion. A total of seven articles were finally included in the review: one article described the use of dental-CT in vivo [28], and six described the use of CBCT both in in vivo and in ex vivo studies [22-27]. Data about study design, population, and device used are summarized in Table 1.

Each of the included studies was evaluated by two authors (SC and ST) for risk of bias analysis, whose results are presented in Table 2.

In pooled analysis, the second mesiobuccal canal was present in $59.32 \%$ of the examined teeth (out of a total of 1964 teeth), and it was evaluated as completely independent (noncommunicating) in $58.45 \%$ of the teeth presenting the canal $(N=1165)$. Data about frequency of the presence of the second mesiobuccal canal with different detection methods are summarized in Table 3. 
TABLE 1: Study characteristics.

\begin{tabular}{|c|c|c|c|c|c|c|}
\hline Authors & Year & Study & Device & Characteristics (machine; voxel size) & Population & Patients/teeth \\
\hline \multicolumn{7}{|l|}{$\mathrm{CBCT}$} \\
\hline Filho et al. [22] & 2009 & In vivo & СBCT & i-CAT; $0.2 \mathrm{~mm}^{3}$ & Brazil & $\mathrm{NR} / 54$ \\
\hline Blattner et al. [23] & 2010 & In vitro & СBCT & i-CAT; NR & - & $\mathrm{NE} / 20$ \\
\hline Neelakantan et al. [24] & 2010 & Ex vivo & СВСТ & $3 \mathrm{D}$ accuitomo; $0.125 \mathrm{~mm}^{3}$ & India & $\mathrm{NR} / 220$ \\
\hline Zhang et al. [25] & 2011 & In vivo & СВCТ & $3 \mathrm{D}$ accuitomo; $0.125 \mathrm{~mm}^{3}$ & China & $269 / 299$ \\
\hline Lee et al. [26] & 2011 & In vivo & СBCT & Volux; $0.167 \mathrm{~mm}^{3}$ & Republic of Korea & $276 / 458$ \\
\hline Kim et al. [27] & 2012 & In vivo & СВCТ & Dinnova; $0.167 \mathrm{~mm}^{3}$ & Republic of Korea & $415 / 814$ \\
\hline \multicolumn{7}{|l|}{ Dental CT } \\
\hline Rathi et al. [28] & 2010 & In vivo & Dental CT & Somatom; $1 \mathrm{~mm}^{3}$ & India; age: $11-77 \mathrm{y}$ & $100 / 100$ \\
\hline
\end{tabular}

NR: Not reported; NE: Not estimable; MB: mesiobuccal.

TABLE 2: Risk of bias evaluation.

\begin{tabular}{|c|c|c|c|c|c|c|c|}
\hline Authors & Year & Study & Number of teeth & Data reporting & Aims of the study & Individual data & Population characteristics \\
\hline \multicolumn{8}{|l|}{ CBCT } \\
\hline Filho et al. [22] & 2009 & In vivo & Low & Moderate & Low & Low & Low \\
\hline Blattner et al. [23] & 2010 & In vitro & Moderate & Low & Low & Low & Low \\
\hline Neelakantan et al. [24] & 2010 & Ex vivo & Low & Low & Low & Low & Low \\
\hline Zhang et al. [25] & 2011 & In vivo & Low & Low & Low & Low & Low \\
\hline Lee et al. [26] & 2011 & In vivo & Low & Low & Low & Low & Low \\
\hline Kim et al. [27] & 2012 & In vivo & Low & Low & Low & Low & Low \\
\hline \multicolumn{8}{|l|}{ Dental CT } \\
\hline Rathi et al. [28] & 2010 & In vivo & Low & Low & Low & Low & Low \\
\hline
\end{tabular}

Four studies presented data that could be classified according to the Vertucci classification of root canal morphology [24-27]. The data are summarized in Table 4. More than $37 \%$ of the classified 1741 teeth included in this analysis belonged to type IV, while $36.18 \%$ belonged to type I. These two types were the most frequently detected morphologies.

Comparison of the different detection systems showed that in CBCT the MB2 was detected in $61.84 \%$ of teeth, while dental-CT showed MB2 presence in 39\% of teeth.

\section{Discussion}

The present study was aimed to systematically review the root canal anatomy of the mesiobuccal roots of permanent maxillary first molars as shown in CT images.

The retrieved data showed that the detection of a separate mesiobuccal canal occurred in nearly two-thirds of the cases. The common occurrence of two canals in the mesiobuccal roots has a major implication in endodontics when performing a root canal therapy in maxillary first molars.

A systematic review of the literature performed by Cleghorn and coworkers in 2006 [8] estimated the anatomy of the permanent maxillary first molar through a meta-analysis of data of about 8399 teeth from 34 laboratory studies and of 2576 teeth from 14 clinical studies. They reported that the incidence of two canals in the mesiobuccal root was $56.8 \%$, which is similar to the results of the present study.

An issue to be considered is the age and gender of the subjects. Several authors found that a second mesiobuccal canal is less frequent in older subjects due to progressive calcification and obturation $[8,30-33]$. As reported by other authors, there is conflicting evidence regarding differences related to gender of the subjects $[11,32]$.

The present study also showed that, if an MB2 was present it was mostly not merged with the primary one there were two separate apexes and two entrances without any merging (Vertucci Class IV [29]). This finding, which was also confirmed by previous systematic reviews $[8,9$, 34], may have clinical relevance. The detection of a second mesiobuccal canal is mandatory for complete sterilization and filling of the root canal system, in order not to leave a pathway for bacterial migration towards the apex or a reservoir for microorganisms.

Some studies investigated the use of magnification devices (microscope or magnifying loupes) as an adjuvant for the detection of a second mesiobuccal canal [34-37]. One of these studies showed that the MB2 was detected in $71.1 \%$ of maxillary first molars when using a microscope, in $62.5 \%$ of these teeth when using dental loupes, and only in $17.2 \%$ of these teeth without any magnification [36]. These results are similar to those reported in other studies and are comparable to the frequencies reported in the present review for CT.

However, the use of CBCT is considered very important for an adequate planning of endodontic surgery because of the capability to detect anatomical variations [17, 38]. The use of CBCT enables reproduction of three-dimensional anatomy, allowing the evaluation of bone thickness and the relationships between root apices, lesions, and anatomical structures such as the maxillary sinus [38-41]. 
TABLE 3: Evaluation of the presence of second mesiobuccal canal.

\begin{tabular}{|c|c|c|c|c|c|c|c|c|c|c|}
\hline \multirow{2}{*}{ Authors } & \multirow{2}{*}{$N$} & \multicolumn{3}{|c|}{ Presence of MB } & \multicolumn{3}{|c|}{ MB independent } & \multicolumn{3}{|c|}{ MB1 merge MB2 } \\
\hline & & $n$ & $\%$ & Cumulative $\%$ & $n$ & $\%$ & Cumulative $\%$ & $n$ & $\%$ & Cumulative \% \\
\hline \multicolumn{11}{|l|}{ CBCT } \\
\hline Filho et al. [22] & 54 & 21 & 38.89 & & 1 & 4.76 & & 20 & 95.24 & \\
\hline Blattner et al. [23] & 19 & 11 & 57.89 & & NR & - & & NR & - & \\
\hline Neelakantan et al. [24] & 220 & 99 & 45 & & 85 & 85.86 & & 12 & 12.12 & \\
\hline Zhang et al. [25] & 299 & 156 & 52.17 & & 109 & 69.87 & & 22 & 14.1 & \\
\hline Lee et al. [26] & 458 & 329 & 71.83 & & 160 & 48.63 & & 152 & 46.2 & \\
\hline Kim et al. [27] & 814 & 510 & 62.65 & & 326 & 63.92 & & 165 & 32.35 & \\
\hline Total & 1864 & 1126 & & 61.84 & 681 & & 63.93 & 371 & & 39.68 \\
\hline \multicolumn{11}{|l|}{ Dental CT } \\
\hline Rathi et al. [28] & 100 & 39 & 39 & & NR & 一 & & NR & - & \\
\hline \multirow[t]{2}{*}{ Total } & 100 & 39 & & 39 & 0 & & 0 & 0 & & 0 \\
\hline & 1964 & 1165 & & 59.32 & 681 & & 58.45 & 371 & & 31.85 \\
\hline
\end{tabular}

$N$ : total number of teeth; $n$ : number of teeth belonging to a category; NR: not reported; Cumulative \%: weighted mean proportion of teeth.

TABLE 4: Root canal morphology following the Vertucci classification [29].

\begin{tabular}{|c|c|c|c|c|c|c|c|c|c|c|}
\hline \multirow[b]{2}{*}{ Authors } & \multirow[b]{2}{*}{$N$} & \multicolumn{9}{|c|}{ Vertucci classification } \\
\hline & & $\begin{array}{l}\text { T I } \\
(1)\end{array}$ & $\begin{array}{c}\text { T II } \\
(2-1)\end{array}$ & $\begin{array}{c}\text { T III } \\
(1-2-1)\end{array}$ & $\begin{array}{c}\text { T IV } \\
(2)\end{array}$ & $\begin{array}{l}\mathrm{T} V \\
(1-2) \\
\end{array}$ & $\begin{array}{c}\text { T VI } \\
(2-1-2)\end{array}$ & $\begin{array}{c}\text { T VII } \\
(1-2-1-2)\end{array}$ & $\begin{array}{c}\text { T VIII } \\
(3)\end{array}$ & NC \\
\hline Neelakantan et al. [24] & 220 & 114 & 12 & 0 & 85 & 0 & 0 & 0 & 2 & 0 \\
\hline Zhang et al. [25] & 299 & 113 & 22 & 0 & 109 & 25 & 0 & 0 & 0 & 0 \\
\hline Lee et al. [26] & 458 & 129 & 152 & 0 & 160 & 11 & 0 & 0 & 6 & 0 \\
\hline Kim et al. [27] & 814 & 292 & 164 & 2 & 326 & 16 & 1 & 0 & 0 & 0 \\
\hline Total & & 648 & 350 & 2 & 680 & 52 & 1 & $\mathbf{0}$ & 8 & $\mathbf{0}$ \\
\hline$\%$ & & 36.18 & 19.54 & 0.11 & 37.97 & 2.90 & 0.06 & 0.00 & 0.45 & 0.00 \\
\hline
\end{tabular}

$N$ : number of teeth.

In the present review, the included articles seemed to be very heterogeneous in population characteristics and study methodology, limiting the external validity of the results. Also, different CBCT devices were used, which should be considered as an important confounding factor, thus limiting the ability to perform a full meta-analysis.

Despite these limitations, the present study showed that CBCT may be useful in detecting the presence of a second mesiobuccal canal in permanent first molars. This can be considered as an important adjunct in pretreatment assessment for endodontic procedures, especially in periapical surgery.

\section{Conflict of Interests}

The authors declare that they have no conflict of interests.

\section{References}

[1] S. D. Bernstein, A. J. Horowitz, M. Man et al., "Outcomes of endodontic therapy in general practice: a study by the practitioners engaged in applied research and learning network," Journal of the American Dental Association, vol. 143, no. 5, pp. 478-487, 2012.
[2] M. Song, H. C. Kim, W. Lee, and E. Kim, "Analysis of the cause of failure in nonsurgical endodontic treatment by microscopic inspection during endodontic microsurgery," Journal of Endodontics, vol. 37, no. 11, pp. 1516-1519, 2011.

[3] F. Faramarzi, H. Fakri, and H. H. Javaheri, "Endodontic treatment of a mandibular first molar with three mesial canals and broken instrument removal," Australian Endodontic Journal, vol. 36, no. 1, pp. 39-41, 2010.

[4] D. Ricucci and J. F. Siqueira Jr., "Anatomic and microbiologic challenges to achieving success with endodontic treatment: a case report," Journal of Endodontics, vol. 34, no. 10, pp. 12491254, 2008.

[5] F. S. Weine, H. J. Healey, H. Gerstein, and L. Evanson, "Canal configuration in the mesiobuccal root of the maxillary first molar and its endodontic significance," Oral Surgery, Oral Medicine, Oral Pathology, vol. 28, no. 3, pp. 419-425, 1969.

[6] D. Ricucci and J. F. Siqueira Jr., "Fate of the tissue in lateral canals and apical ramifications in response to pathologic conditions and treatment procedures," Journal of Endodontics, vol. 36, no. 1, pp. 1-15, 2010.

[7] Y. L. Ng, T. H. Aung, A. Alavi, and K. Gulabivala, "Root and canal morphology of Burmese maxillary molars," International Endodontic Journal, vol. 34, no. 8, pp. 620-630, 2001.

[8] B. M. Cleghorn, W. H. Christie, and C. C. S. Dong, "Root and root canal morphology of the human permanent maxillary first 
molar: a literature review," Journal of Endodontics, vol. 32, no. 9, pp. 813-821, 2006.

[9] J. C. Kulid and D. D. Peters, "Incidence and configuration of canal systems in the mesiobuccal root of maxillary first and second molars," Journal of Endodontics, vol. 16, no. 7, pp. 311-317, 1990.

[10] J. J. Stropko, "Canal morphology of maxillary molars: clinical observations of canal configurations," Journal of Endodontics, vol. 25, no. 6, pp. 446-450, 1999.

[11] F. S. Weine, S. Hayami, G. Hata, and T. Toda, "Canal configuration of the mesiobuccal root of the maxillary first molar of a Japanese sub-population," International Endodontic Journal, vol. 32, no. 2, pp. 79-87, 1999.

[12] J. Wolcott, D. Ishley, W. Kennedy, S. Johnson, S. Minnich, and J. Meyers, "A $5 \mathrm{yr}$ clinical investigation of second mesiobuccal canals in endodontically treated and retreated maxillary molars," Journal of Endodontics, vol. 31, no. 4, pp. 262-264, 2005.

[13] A. M. Alavi, A. Opasanon, Y. L. Ng, and K. Gulabivala, "Root and canal morphology of Thai maxillary molars," International Endodontic Journal, vol. 35, no. 5, pp. 478-485, 2002.

[14] X. L. Weng, S. B. Yu, S. L. Zhao et al., "Root canal morphology of permanent maxillary teeth in the han nationality in Chinese Guanzhong area: a new modified root canal staining technique," Journal of Endodontics, vol. 35, no. 5, pp. 651-656, 2009.

[15] T. Yoshioka, I. Kikuchi, Y. Fukumoto, C. Kobayashi, and H. Suda, "Detection of the second mesiobuccal canal in mesiobuccal roots of maxillary molar teeth ex vivo," International Endodontic Journal, vol. 38, no. 2, pp. 124-128, 2005.

[16] I. A. Sherwood, "Pre-operative diagnostic radiograph interpretation by general dental practitioners for root canal treatment," Dentomaxillofacial Radiology, vol. 41, no. 1, pp. 43-54, 2012.

[17] S. Patel, "New dimensions in endodontic imaging-part 2: cone beam computed tomography," International Endodontic Journal, vol. 42, no. 6, pp. 463-475, 2009.

[18] D. Schulze, M. Heiland, H. Thurmann, and G. Adam, "Radiation exposure during midfacial imaging using 4- and 16slice computed tomography, cone beam computed tomography systems and conventional radiography," Dentomaxillofacial Radiology, vol. 33, no. 2, pp. 83-86, 2004.

[19] W. C. Scarfe, M. D. Levin, D. Gane, and A. G. Farman, "Use of cone beam computed tomography in endodontics," International Journal of Dentistry, vol. 2009, Article ID 634567, 20 pages, 2009.

[20] M. A. Mora, A. Mol, D. A. Tyndall, and E. M. Rivera, "In vitro assessment of local computed tomography for the detection of longitudinal tooth fractures," Oral Surgery, Oral Medicine, Oral Pathology, Oral Radiology and Endodontology, vol. 103, no. 6, pp. 825-829, 2007.

[21] A. G. Farman and T. T. Farman, "A comparison of 18 different x-ray detectors currently used in dentistry," Oral Surgery, Oral Medicine, Oral Pathology, Oral Radiology and Endodontology, vol. 99, no. 4, pp. 485-489, 2005.

[22] F. B. Filho, S. Zaitter, G. A. Haragushiku, E. A. de Campos, A. Abuabara, and G. M. Correr, "Analysis of the internal anatomy of maxillary first molars by using different methods," Journal of Endodontics, vol. 35, no. 3, pp. 337-342, 2009.

[23] T. C. Blattner, N. George, C. C. Lee, V. Kumar, and C. D. J. Yelton, "Efficacy of cone-beam computed tomography as a modality to accurately identify the presence of second mesiobuccal canals in maxillary first and second molars: a pilot study," Journal of Endodontics, vol. 36, no. 5, pp. 867-870, 2010.
[24] P. Neelakantan, C. Subbarao, R. Ahuja, C. V. Subbarao, and J. L. Gutmann, "Cone-beam computed tomography study of root and canal morphology of maxillary first and second molars in an Indian population," Journal of Endodontics, vol. 36, no. 10, pp. 1622-1627, 2010.

[25] R. Zhang, H. Yang, X. Yu, H. Wang, T. Hu, and P. M. H. Dummer, "Use of CBCT to identify the morphology of maxillary permanent molar teeth in a Chinese subpopulation," International Endodontic Journal, vol. 44, no. 2, pp. 162-169, 2011.

[26] J. H. Lee, K. D. Kim, J. K. Lee et al., "Mesiobuccal root canal anatomy of Korean maxillary first and second molars by conebeam computed tomography," Oral Surgery, Oral Medicine, Oral Pathology, Oral Radiology and Endodontology, vol. 111, no. 6, pp. 785-791, 2011.

[27] Y. Kim, S. J. Lee, and J. Woo, "Morphology of maxillary first and second molars analyzed by cone-beam computed tomography in a Korean population: variations in the number of roots and canals and the incidence of fusion," Journal of Endodontics, vol. 38, no. 8, pp. 1063-1068, 2012.

[28] S. Rathi, J. Patil, and P. P. Jaju, "Detection of mesiobuccal canal in maxillary molars and distolingual canal in mandibular molars by dental CT: a retrospective study of 100 cases," International Journal of Dentistry, vol. 2010, Article ID 291276, 6 pages, 2010.

[29] F. J. Vertucci, "Root canal anatomy of the human permanent teeth," Oral Surgery Oral Medicine and Oral Pathology, vol. 58, no. 5, pp. 589-599, 1984.

[30] F. M. Burke and D. Y. Samarawickrama, "Progressive changes in the pulpo-dentinal complex and their clinical consequences," Gerodontology, vol. 12, no. 12, pp. 57-66, 1995.

[31] D. R. Morse, "Age-related changes of the dental pulp complex and their relationship to systemic aging," Oral Surgery Oral Medicine and Oral Pathology, vol. 72, no. 6, pp. 721-745, 1991.

[32] N. Pattanshetti, M. Gaidhane, and A. M. Al Kandari, "Root and canal morphology of the mesiobuccal and distal roots of permanent first molars in a Kuwait population-a clinical study," International Endodontic Journal, vol. 41, no. 9, pp. 755762, 2008.

[33] R. M. Al Shalabi, O. E. Omer, J. Glennon, M. Jennings, and N. M. Claffey, "Root canal anatomy of maxillary first and second permanent molars," International Endodontic Journal, vol. 33, no. 5, pp. 405-414, 2000.

[34] E. J. Neaverth, L. M. Kotler, and R. F. Kaltenbach, "Clinical investigation (in vivo) of endodontically treated maxillary first molars," Journal of Endodontics, vol. 13, no. 10, pp. 506-512, 1987.

[35] H. E. V. Voorde, D. Odendahl, and J. Davis, "Molar 4th canals: frequent cause of endodontic failure?" Illinois Dental Journal, vol. 44, no. 12, pp. 779-786, 1975.

[36] L. J. Buhrley, M. J. Barrows, E. A. BeGole, and C. S. Wenckus, "Effect of magnification on locating the MB2 canal in maxillary molars," Journal of Endodontics, vol. 28, no. 4, pp. 324-327, 2002.

[37] D. M. Nosonowitz and M. R. Brenner, "The major canals of the mesiobuccal root of the maxillary 1st and 2nd molars," The New York Journal of Dentistry, vol. 43, no. 1, pp. 12-15, 1973.

[38] M. Rigolone, D. Pasqualini, L. Bianchi, E. Berutti, and S. D. Bianchi, "Vestibular surgical access to the palatine root of the superior first molar: "low-dose cone-beam" CT analysis of the pathway and its anatomic variations," Journal of Endodontics, vol. 29, no. 11, pp. 773-775, 2003.

[39] S. Patel and A. Dawood, "The use of cone beam computed tomography in the management of external cervical resorption 
lesions," International Endodontic Journal, vol. 40, no. 9, pp. 730-737, 2007.

[40] S. Taschieri, M. D. Fabbro, S. Corbella, T. Weinstein, G. Rosano, and I. Tsesis, "Endoscopic minimally invasive management of a periradicular lesion invading the maxillary sinus," Journal of Oral Science, vol. 53, no. 4, pp. 533-538, 2011.

[41] K. Oberli, M. M. Bornstein, and T. von Arx, "Periapical surgery and the maxillary sinus: radiographic parameters for clinical outcome," Oral Surgery, Oral Medicine, Oral Pathology, Oral Radiology and Endodontology, vol. 103, no. 6, pp. 848-853, 2007. 


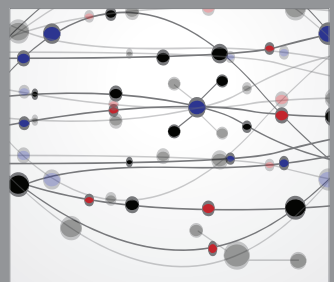

The Scientific World Journal
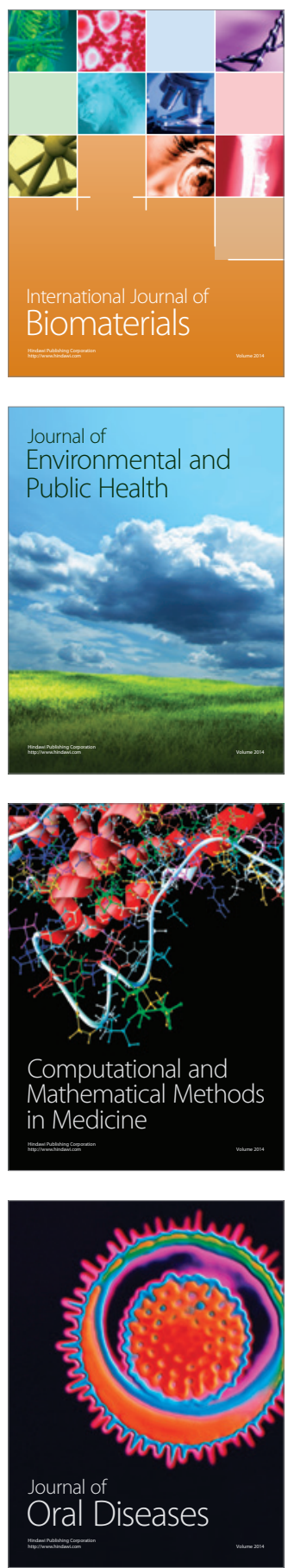
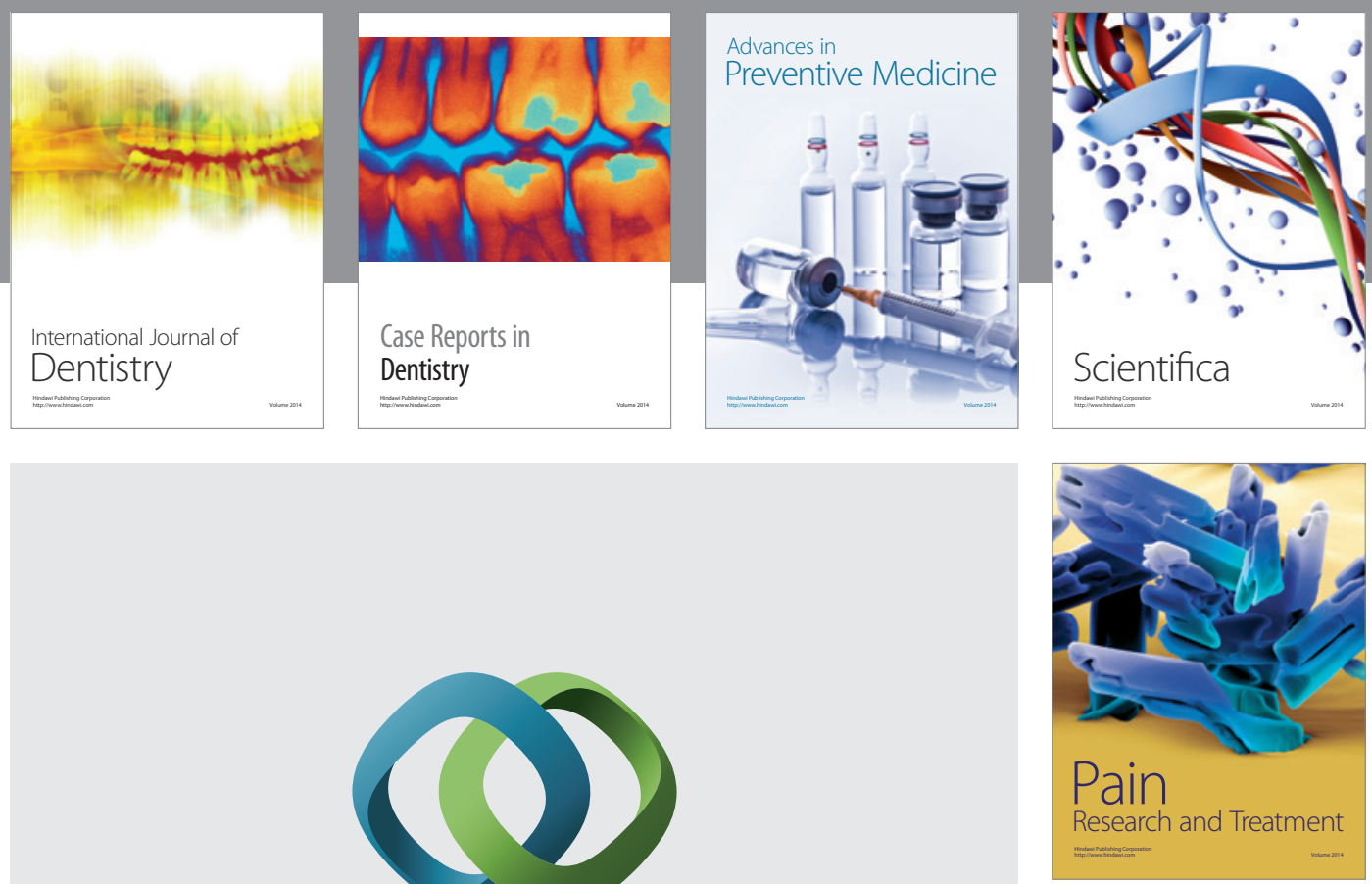

\section{Hindawi}

Submit your manuscripts at

http://www.hindawi.com
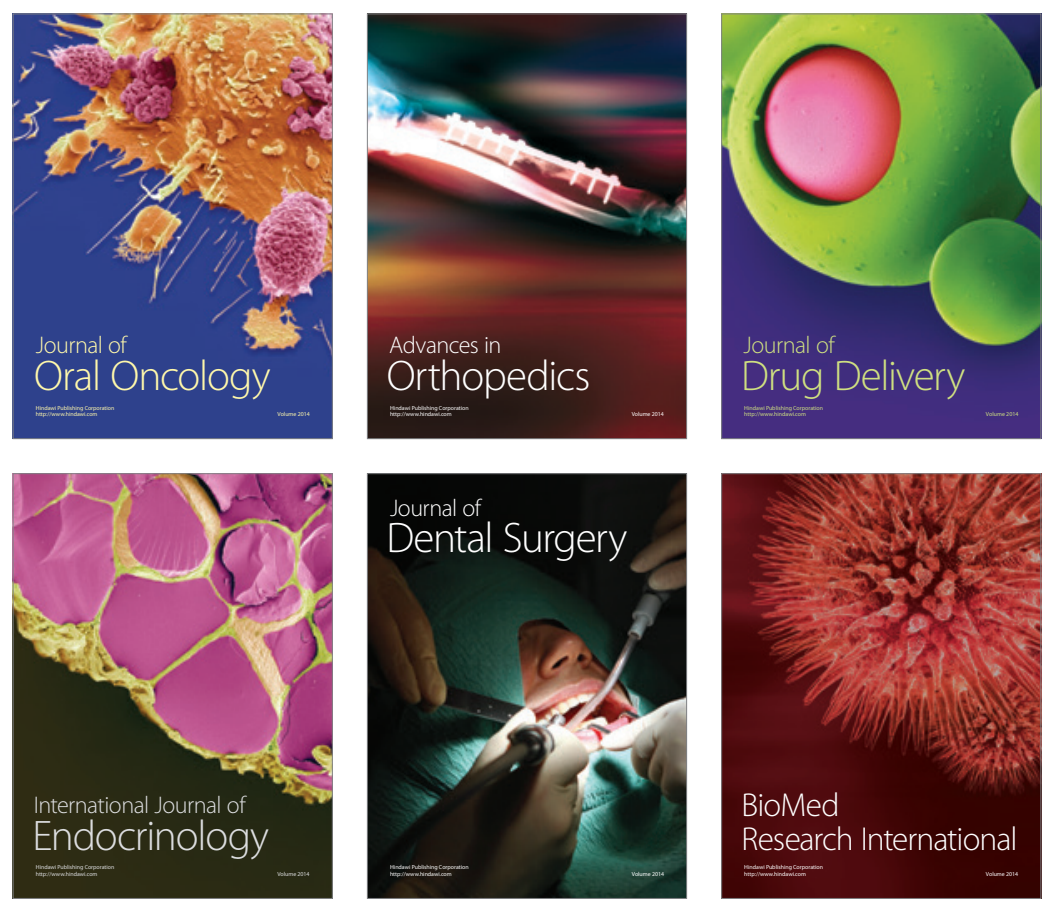

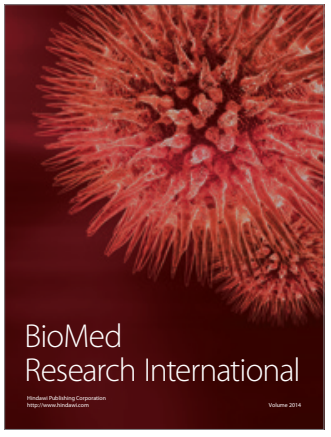

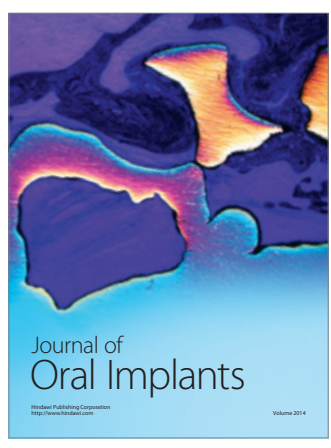
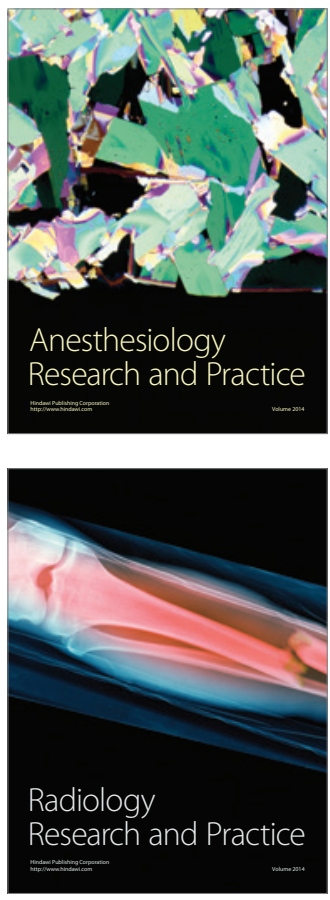